\title{
SINGLE LAYER EXTRA-MUCOSAL INTERRUPTED ANASTOMOSES; REVALIDATED
}

\author{
Bilal Khattak ${ }^{1}$, Faiz-Ur-Rahman ${ }^{1}$, Irfan-UI-Islam Nasir ${ }^{1}$, Muhammad Iftikhar ${ }^{2}$, \\ Imtiaz Ahmad Khattak ${ }^{3}$, Zia-Ur-Rahman ${ }^{1}$
}

\author{
1. Town Teaching Hospital \\ 2. Hayatabad Medical Complex \\ 3. Khyber Teaching Hospital
}

\begin{abstract}
Objective:

To evaluate the safety regarding anastomotic failure of single layer interrupted extra mucosal intestinal anastomosis in comparison with double layer intestinal anastomosis

\section{Methodology:}

This prospective comparative study was conducted in surgical $A$ unit of Lady reading Hospital Peshawar from 1st June 2007 to 1st February 2008 (8 months). Patients were divided into two groups, each comprising 60 patients. First 60 consecutive patients were included in Group A, for single layer extra mucosal anastomosis while Group B included last 60 consecutive patients for double layer inverting anastomosis (continuous inner and interrupted outer Lambert sutures). All the cases were admitted through OPD and emergency. The safety of two techniques of anastomosis was analyzed by comparing the outcome in terms of complications.
\end{abstract}

\section{Results:}

In this study, anastomosis leakage occurred only in 4 (3.33\%) patients, one (1.67\%) in group $A$ and three $(5 \%)$ in group $B$ with a $P$-Value 0.138. Mean age of patient in group $A$ was 36.15 years (+/- 6.0 years) and in group $B$ was 33.25 years (+/- 5.5 years).

\section{Conclusion:}

Single layer extra-mucosal anastomosis has least anastomotic leakage and other complication like wound infection, septicemia, and collection and burst abdomen than in patients with double layer investing anastomosis.

\section{Key Words:}

Anastomosis, extra-mucosal, single layer and leakage

\section{INTRODUCTION}

Intestinal anastomosis is a surgical procedure to establish communication between two formerly distant portions of the intestine. This procedure restores intestinal continuity after

\begin{tabular}{c}
\hline Correspondence: \\
Dr. Bilal Khattak \\
Town Teaching Hospital \\
Contact:0333-9254986 \\
Email: drbilalkhattak@yahoo.com \\
\hline https://doi.org/10.37762/jgmds.2-1.59
\end{tabular}
removal of a pathological condition affecting the bowel. Intestinal anastomosis is one of the most commonly performed surgical procedures, especially in the emergency setting, and is also commonly performed in the elective setting when resections are carried out for benign or malignant lesions of the gastrointestinal tract $^{1}$. Controversy regarding single versus double layer anastomosis goes as Senn after Hallstead in 1883, proposed interrupted extra mucosal suturing. Then Senn in 1887 advised 
double layer anastomosis. By 1931 more than 52 techniques for ( $\mathrm{Gl}$ anastomosis) had been described. ${ }^{2,3}$ A number of anastomotic techniques are available but because all compromise healing none can be considered prefect. ${ }^{4} \mathrm{An}$ insecure intestinal anastomosis is an unacceptable iatrogenic hazard. The breakdown of suture line or anastomosis may result in haemorrhage, leakage, stenosis, diverticulum formation and ultimately faecal fistula with septic complications. The sound healing process of anastomosis depends mainly on anastomosis technique, which is the most important determinant. ${ }^{5}$ The mechanical strength of the intact intestinal wall was conditioned by the submucosa and muscularis, while the serosa and mucosa showed no significant strength. ${ }^{6}$, 7. Double layer anastomosis produces mucosal inversion and serosal apposition. The first layer is done by taking sutures through all coats of the gut wall and in the second layer serosa is approximated. The inner layer is believed to be haemostatic but there are chances of strangulation of mucosa due to damage to submucosal vascular plexus. ${ }^{8}$ In single layer technique; only seromuscular layer of the gut wall is approximated. This technique incorporates the strongest layer of the gut and causes minimal damage to the submucosal vascular plexus. ${ }^{9}$

The objective of this study was to evaluate the safety of single layer interrupted extramucosal intestinal anastomosis in comparison with double layer intestinal anastomosis with hypothesis that both are equal in term of safety( judge by the time needed by the gut to heal and return of bowel sounds).

\section{METHODOLOGY}

This prospective comparative study was conducted in Surgical A unit of lady Reading Hospital, Peshawar. The sample size was 120 patients from outpatient department and emergency department. Sampling was done through simple convenience sampling and first sixty patients were allotted to single layer anastomosis (group A) and 60 patients to double layer anastomosis (group B). Pre-operative preparation of the patients was different in those cases who were admitted through causality as compared to those patients who were admitted through OPD.The reason was that the patients who were admitted through causality were having intestinal obstruction, acute abdomen or trauma, all needing urgent exploration as compared to the patients admitted through OPD.OPD patients were admitted two to three days before the surgery in order to fully prepare the patient.

All adults patients (>14) of age of either sex were included in the study. In emergency only those patients were selected in whom segmental resection and anastomosis was performed. Patients with oesophageal, gastric, gastrojejunal and colo-anal anastomosis were excluded from the study. All the data was entered on a pre-designedproforma which included: Demographic detail, operative findings, operating technique, operative and postoperative complications especially anastomotic leak, wound infection, cardiopulmonary complications, hospital mortality and duration of hospital stay. Sample size was calculated through computer based software" Sample size determination in health studies by WHO" and expected prevalence of $35 \%{ }^{10}$ expected error of $8 \%$ and $95 \%$ level of confidence. The data was processed on the SPSS version 16. Student's t-test was used to analyze the continuous data. Fischer exact test was used to determine the statistical significance of categorical data. A p-value of less than 0.05 was considered significant.

\section{RESULTS}


Among 120 patients, Mean age of patient in group A was 36.15 years (S.D=6.0) and in group $B$ was 33.25 years (S.D=5.5). In this study, the anastomoses were constructed in all areas of small and large intestine, from duodeno-jejunal junction up to the upper rectum (i.e. above the peritoneal reflection). Table 1 shows the higher no. of anastomoses were done in ileum i.e. 58 followed by colo-colic anastomosis. Only 3 anastomoses were done in colorectal region in which Harttman's reversal was done. In this study, anastomotic leakage occurred in 4 patients, one in group $A$ and three in group B with a P-value 0.138. The patient which leaked in group A was operated for obstructed paraumblical hernia in emergency with ileal resection and end to end anastomsis. Three patients leaked in group B, two elective list and one of emergency. In group B elective patients, one was operated for ileostomy reversal which leaked on $4^{\text {th }}$ Post-operative day and second was elderly patient who was operated for sigmoid volvulus in which resection and end to end anastomosis was done and it leaked on $5^{\text {th }}$ post-operated day. Wound infection occurred in 13 patients, 7 in group a and 6 in group B. Intra- abdominal wound infection/collection occurred in 4 patients, all of them of group B. Septicemia occurred equally in both groups. Burst abdomen occurred in three patients, all of them belonging to group B. Melina occurred only in one patient in group A, which settled with time (Table-2). Overall, four patients died, $3(5 \%)$ in group B and only one $(1.7 \%)$ patient in group $A$.

Table-1: Different Sites Of Anastomosis In Groups

\begin{tabular}{|c|c|c|c|}
\hline & \multicolumn{2}{|c|}{ Group } & \multirow{2}{*}{ Total } \\
\hline & Group A & Group B & \\
\hline Site of & 33 & 25 & 58 \\
\hline Anastomosis Jejunum & 5 & 7 & 12 \\
\hline Jejuno-Ileal & 5 & 5 & 10 \\
\hline Colo-colic & 11 & 16 & 27 \\
\hline Ileo Colic & 4 & 6 & 10 \\
\hline Colorecta & 2 & 1 & 3 \\
\hline Total & 60 & 60 & 120 \\
\hline
\end{tabular}

Table-2: Overall Complications Rates In Two Groups

\begin{tabular}{|l|c|c|c|}
\hline \multirow{2}{*}{ COMPLICATIONS } & \multicolumn{2}{|c|}{ Groups } & \multirow{2}{*}{ Total } \\
\cline { 2 - 3 } & Group A & Group B & \\
\hline Overall Leakage rate & 1 & 3 & 04 \\
\hline Wound Infection & 07 & 06 & 13 \\
\hline Intra abdominal abscess / collection & 0 & 4 & 04 \\
\hline Septicemia & 02 & 02 & 04 \\
\hline Burst abdomen & 00 & 03 & 03 \\
\hline Mortality & 01 & 03 & 04 \\
\hline Melena & 01 & & 01 \\
\hline None & 48 & 39 & 87 \\
\hline Total & $\mathbf{6 0}$ & $\mathbf{6 0}$ & $\mathbf{1 2 0}$ \\
\hline
\end{tabular}

\section{DISCUSSION}

The most important aspect of this study was to compare anastomotic leakage along with other complications. In our study anastomosis leakage occurred in 4 (3.33\%) out of 120 patients. Out of this, 1 patient $(0.02 \%)$ was in group $A$ and 3 patients $(5 \%)$ in group B.According to various studies, the leakage rate for single layer extra mucosal anastomosis varies from $0.002-7.7 \%{ }^{11-12}$ and result of this study for extra mucosal anastomosis is in the lower limit of these studies. 
According to Leslie $\mathrm{A}^{13}$ extra mucosal technique is a gold standard for anastomosis involving small and large intestine. According to his study, leakage rate was $0.002 \%$ (one leak in 553 patients) which was even lower than our study. The leakage rate mentioned in literature for the double layer technique vary from $1.5-7.8 \%^{7,9,14}$ and the result of this study are within this range but according to Samiullah et al, the leakage rate for double layer anastomosis may be as high as $13.11 \%{ }^{8}$

Subcutaneous wound infection occurred in 10.8\% (13 out of 120) patients. Seven patients were in group a (11.7\%) and six patients in group B (10\%). Out of 13 patients 9 were operated in emergency. The rate of wound infection in this study falls in the range mentioned in literature i.e., $2-11 \% .{ }^{15},{ }^{16}$ A study conducted by khan $N^{17}$ in the same hospital mentioned infection rate of $15 \%$, which is higher than our study. This may be due to a higher wound infection rate of colostomy closure in his study.

\section{CONCLUSION}

Extra mucosal interrupted ananstomosis is associated with less leakage rate and post op complications i.e. intra abdominal collection, fever, sepsis in comparision to double layer anastomosis.

\section{REFERENCES}

1. Ayub $M$, sheikh $R$, Gangat $S$, lqbal $A$, Single layer anastomosis versis two layer anastomosis. $A$ prospective study. Pak J Surg. 2011;25(3):277-80

2. Sajid SM, Rafi SM, Siddiqui S, Baig M. Single layer anastomosis verses double layer suture anastomosis of GI tract. Cochrane colorectal cancer group:Jan 2012;34(4):154-9

3. Nyhus LM, Baker RJ (eds) Mastery of surgery. Vol $2^{\text {nd }}$ ed. Chicago:1992; 1151-61

4. Ashkanani F, Krukowshi ZH, Intestinal anastomosis. Surgery international 2002, 57:104-7

5. Tarar NA, Evaluation of extra mucosal single layer intestinal anastomosis technique : Pak Armed Forces Med J: Dec 2003; 53(2)- 124-5

6. Egorov VI, Schastlivtsev V, Turusov RA, Baranov AO. Participation of intestinal layers in supplying of the mechnical strength of intact and sutured gut. EurSurg Res 2002;34:425-31

7. Egorov VI, Schastlivtsev IV, Prut EV, Baranov AO, Turusov RA. Mechanical properties of the human gastrointestinal tract. J Biomech 2002;35:1417-25

8. Samiullah, Israr M, Zada N. Comparison of single layer interrupted intestinal anastomosis with double layer intestinal anastomosis. J Postgrad Med Inst 2003; 17:263-6.

9. Burch JM, Franciose RJ, Moore EE, Biffi WL, Offner PJ. Single layer continuous versus two layers interrupted intestinal anastomosis; a prospective randomized trail. Ann Surg 2000;231:832-7

10. Sandrasegan K, Dean D, John C, Thomas J. Samll bowl complication of major gastrointestinal tract surgery. Am J Roentol:2005;185(3)-671-81

11. Bruse J, Krukowski EM, Park KGM. Systemic review of the definition and measurement anastomotic leak after gastrointestinal surgery. Br J Surg 2001; 88: 1157-68.

12. Golub R, Golub RW, Cantu RJ, Stein HD. A multivariate analysis of factors contributing to leakage of intestinal anastomosis. J Am Collsurg 1997; 184(4):364-72. 
13. Leslie A, Steele RJ. The interrupted serosubmucosal anastomosis-still the gold standard. Colorectal Dis 2003;5(4):362-6

14. Ordirica-Flares RM, Bracho-Blanchet E, Nieto-zermeno J, Reyes-Retana R, Tovilla-Mercado JM et al. intestinal anastomosis in children: a comparative study between two techniques. J pediatrSurg 1998;33:1757-59

15. Ishida H, Yokoyama M, Nakada H, Inokuma S, Hashimoto D. Impact of oral antimicrobial prophylaxis on surgical site infection and methicillin- resistant. Staphylococcus aureus infection in elective colorectal surgery; results of a prospective randomized trial. Surgery today 2001;31:979-83

16. Matheson NA. Prospective audit of an extramucosal technique for intestinal anastomosis. Br J Surg 1992;79:84

17. Khan N, Rahman A, Sadiq MD. Single layer interrupted serosubmucosal (extramucosal) intestinal anastomosis. J Med Sci 2006:14:10-3.

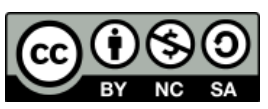

LICENSE: JGMDS publishes its articles under a Creative Commons Attribution Non-Commercial Share-Alike license (CC-BY-NC-SA 4.0). COPYRIGHTS: Authors retain the rights without any restrictions to freely download, print, share and disseminate the article for any lawful purpose. It includes scholarly networks such as Research Gate, Google Scholar, LinkedIn, Academia.edu, Twitter, and other academic or professional networking sites. 